\title{
PEMBERDAYAAN KELOMPOK USAHA TANI DALAM UPAYA PENINGKATAN KESEJAHTERAAN MASYARAKAT (Studi Di Desa Kampani Kecepatan Wadaga Kabupaten Muna Barat)
}

\author{
Wa Ode Haspianti ${ }^{1}$, Syaifuddin S. Kasim² ${ }^{2}$, Aryuni Salpiana Jabar ${ }^{3}$ \\ ${ }^{123}$ Universitas Halu Oleo \\ Email: waodehaspianti09@gmail.com
}

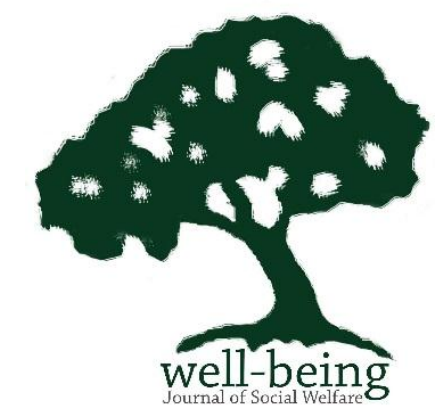

\begin{abstract}
ABSTRAK
The purpose of this study was to determine the stages of the implementation of the empowerment of farming groups in an effort to improve community welfare in Kampani Village, Wadaga District, West Muna Regency. The method used in this research is through field research by using interview and observation techniques to empower farming groups in an effort to improve community welfare. The results showed that the implementation of the empowerment of farming groups in an effort to improve the welfare of the community by fostering a desire to change. Develop the ability to participate, increase the role in the desire for empowerment and also the development of motivations for change.
\end{abstract}

Keywords: Empowerment; Farmer Business Groups; Community; Welfare

\section{PENDAHULUAN}

Upaya memberdayakan rakyat harus dilakukan melalui enciptakan suasana atau iklim yang memungkinkan potensi masyarakat untuk berkembang. Kondisi ini berdasarkan asumsi bahwa setiap kelompok dan masyarakat memiliki potensi yang dapat dikembangkan (Kartasasmita, 1995). Haida (2015) Pemberdayaan adalah serangkaian kegiatan untuk memperkuat kekuasaan atau kebudayaan kelompok lemah dalam masyarakat, termasuk kelompokkelompok yang mengalami masalah kemiskinan dan mempunyai tujuan uantuk mencapai sebuah perubahan sosial yaitu masyarakat yang berdaya, memiliki kekuasaan atau mempunyai pengetahui, dan kemampuan dalam memenuhi kebutuhan hidupnya baik yang bersifat fisik, ekonomi, maupun sosial.

Pelaksanaan dan Tahapan Pemberdayaan Masyarakat Tani (Chabib, 2014) menyebutkan Pelaksanaan pemberdayaan merupakan salah satu bagian dari manajemen program, pelaksanaan atau yang biasa disebut dengan pergerakan merupakan suatu keseluruhan usaha, teknik, dan metode untuk mendorong para anggota atau organisasi agar mau dan ikhlas bekerja dengan sebaik mungkin demi tercapiannya tujuan organisasi dengan efisien, efektif dan ekonomis. Teknik Pemberdayaan Masyarakat Tani (Suharto, 2010) yaitu pendekatan dan teknik-teknik peribatan masyarakat dalam proses-proses pemikiran yang berlangsung kegiatan-kegiatan perencanaan dan pelaksanaan serta pemantauan dan efaluasi program pembangunan masyarakat.

Tujuan pemberdayaan masyarakat Tujuan dari pemberdayaan Haida, 2015 Mengenbagkan kemapuan masyarakat lapisan bawah dalam mengidentifikasikan kebutuhan mendaoatkan sumber daya dalam memenuhi, dan pemberdayakan mereka secara bersama- sama.

Pengertian Tani adalah sekumpulan orang-orang tani atau yang terdiri dari tani maupum tani taruna yang terikan secara informal dalam suatu wilayah kelompok 
atas dasar keseraian dan kebutuhan bersama mengusahakan atau terlibat secara langsung atau tidak langsung, atau sewaktu-waktu dalam kegiatan kelompok usaha tani pada peningkatan kesejahteraan masyarakat dan yang berhubung dengan kehidupan kelompok tani di desa Kampani (Tokok, 1994).

\section{METODE PENELITIAN}

Penelitian ini dilakukan di Desa Kampani Kecamatan Wadaga Kambupaten Muna Barat. Pemilihan lokasi dilakukan dengan berdasarkan pada pertimbangan bahwa di lokasi tersebut, proses pemberdayaan masyarakat pada tahun 2010 kelompok tani yang masih menjalankan kelompok usaha tani secara bersama-bersama untuk peningkatan kesejahtearaan masyarakat tani. Pemilihan informan dalam penelitian ini menggunakan teknik purposive sampling, yaitu pemilihan informan secara sengaja yang ditentukan sendiri oleh peneliti sesuai dengan kebutuhan data. Jenis data yang digunakan dalam penelitian ini adalah jenis data kualitatif, yaitu data berupa hasil wawancara dengan informan yang memberikan gambaran penjelasan dan uraian-uraian dalam bentuk narasi untuk mendekripsikan fokus penelitian yaitu pelaksanan pemberdayaan kelompok usaha.

Sumber Data. Data primer yaitu data yang dikumpulkan melalui observasi atau pengamatan langsung di lokasi penelitian dan hasil wawancara terhadap informan penelitian mengetahui pemberdayaan terhadap kelompok tani. Data Sekunder Data sekunder adalah data yang diperole dari sumber lain dari informan. Data yang merupakan dokumentasi dan notulensi penelitian serta rekaman dalam wawancara penelitian.

Teknik Pengupulan Data. Penelitian lapangan (field research) yaitu terknik dengan mengadakan penelitian langsung di lapangan dengan mengunakan metode. Wawacara Mendalam (Indepth Interview). Wawancara mendalam merupakan proses keterengan untuk tujuan penelitian dengan cara melakukan tanya jawab sambil bertatap muka anatara informan dan pewawacara. Teknik observasi dipergunakan uantuk mengumpulkan data melalui pengamatan dan pencatatan langsung tentang objek yang akan menjadi topik kajian dalam penelitian ini. Dokumentasi merupakan suatu teknik mengumpulkan data yang berbetuk tulisan, gambar atau karya karya monumental.

Teknik Analisa Data. Analisis data dilakukan dengan cara mengelola dan mengkaji setiap data baik berupa hasil pengamatan dan wawancara kemudian di susun secara tertruktur untuk mengungkapkan tentang pemberdayaan kelompok usaha tani dilakukan untuk menjawab permasalahan penelitian. kemudian dianalisis satu persatu dan disesuaikan dengan kumpulkan.

\section{HASIL DAN PEMBAHASAN}

Pelaksanaan Pemberdayaan

Kelompok Usaha Tani Pelaksanaan pemberdayaan adalah suatu kelompok usaha tani untuk peningkatkan masyarakat melaluip kelompok tani.

1. Tahap Perencanaan

Proses awal dalam pelaksanaan pemberdayaan dimana antar ketua dan juga anggota kelompok tani saling bekerjasama untuk merencanakan tugas tugas dan program pemberdayaan apa yang akan dilaksanakan.

2. Tahap Pelaksanaan

Setelah selesai dalam merencanakan program pemberdayaan yang telah disepakati dari hasil musyawarah akan melaksanakan kegiatan penyuluhan, pelatihan tani pupuk kompos selanjutnya itu tahap pelaksanaan program tersebut. 
Menumbuhkan Keinginan Untuk Berubah. Pada mereka terus menerus melakukan perubahan demi menjaga eksistensi mereka dan eksistensi perusahaan mereka agar tidak tergerus oleh kerasnya dunia di era globalisasi ini. Karena sering menjadi kunci dari beberapa orang sukses didunia, maka kita juga perlu melakukan perubahan berkala atau agar bisa menjadi sukses.

Mengembangka Kemampuan Partisipasi. Terhadap partisipasi tani dalam penyuluhan tani partisipatif adalah pendidikan motivasi kelompok tani, dan layanan tim penyuluhan, hubungan yang signifikan antara partisipatif dengan kemampuan kelompok tani memecahkan masalah dengan nilai koefisien korelasi sebesar 0,551. Semakin tinggi kelompok tani berpartisipasi dalam penyuluhan kelompok tani maka meningkatkan kemampuan kelompok tani dalam memecahkan masalahnya

Peningkatan Peran Dalam Keingianan pemberdayaan. Peningkatan peran dalam keingianan pemberdayaan akan dijelaskan peran kualitas kehidupan kerja terhadap keinginan untuk mengundurkan diri dan komitmen organisasi dalam satu konteks yang terintegrasi.

Berkembangnya Motifasi-Motifasi Melakukan Perubahan. Berkembangnya motifasi-motifasi melakukam perubahan sebagai manusia yang menjalani kehidupan tentunya kita tidak lepas dari berbagai macam masalah.

\section{KESIMPULAN}

Berdasarkan hasil penelitian yang telah dilakukan pemberdayaan kelompok usaha tani dalam upaya peningkatan Kesejahteraan Masyarakat di Desa Kampani Kecamatan Wadaga Kabupaten Muna Barat bahwa.

Mempengaruhi kesejahteraan Masyarakat pelaksanan permberdayaan kelompok usaha tani di Desa Kampani Kecamatan Wadaga Kabupaten Muna
Barat yaitu Etos kerja dimana dari hasil wawancara dari semua narasumber bahwa etos kerja merupakan hal yang paling penting dalam kemajuan suatu usaha, kelompok tani dan untuk Perlatan yang digunakan kelompok usaha tani jagung dan kacang tanah mereka mengatakan bahwa peningkatan peralatan sangat dibutuhkan. lain yang mempengaruhi kesejahteraan masyarakat kelompok usaha tani jagung dan kacang tanah yaitu produksi dimana hasil dari kelompok usaha tani jagung kacang tanah bergantung pada bibit yang digunakan semakin banyak bibit yang mereka gunakan semakin banyak pula hasil yang didapatkan. Sedangkan dari segi Pemasaran akses untuk pemasaran masih terbatas sehingga berdampak pada penghasilan kelompok usaha tani jagung dan kacang tanah itu sendiri.

\section{DAFTAR PUSTAKA}

Abdusyani, (2012) sosiologi skematika Teori, terapan. Jakarta: bumi aksara.

Chabi b. Sholeh, (2014) Dealetika Pembangunan dan Pelaksanan Pemberdayaan Masyarakat.

Kartasasmita, Ginjar (1995). Pemberdayaan masyarakat sebuah tinjauan administrasi pidato pengakuan jebatan guru besar dalam ilmu administrasi pada fakultas administrasi. Malang: universitas Brawijaya

Khorun, (2003). Tesis Partisipasi Masyarakat Dalam Pembangunan Desa Studi Kasusproram Bantuan Pelaksanaan Pertisipatif Dikecamatan Bulungbodo Kabupaten Sidoarjo. Didownload dari http://www.google.com tanggal 24 November 2015.

Mandasari, Sutra. (2014), Skripsi:Hubungan Peran Kelompok Tani Dengan Produktivitas Usahatani Benih padi.Prodi Agribisnis.Fakultas 
Sains dan Teknologi. Univesitas Islam Negeri Syarif Hidayatullah. Jakarta.diunduh.

Mardikanto, Totok. (1994). Bunga Rampai Pembangunan Pertan ian sebesar sebela maret Univarsitas pers. Surakaraya

Sofa, Haida. (2015)Skripsi. Pemberdayaan Ekomomi Masyarakat Melalui Kelompok Tani.di Dusun Gondang Desa Campurejo Kecamatan Treteb Kabupaten Temanggung. Prodi Iimu Kesejahteraan Sosial. Fakultas Dakwah dan Komunikasi. Universitas Isilam Negeri Sunan Kalijaga Yogyakarta.

Suharto, Edi. (2010) Membangun Masyarakat Memberdayakan Masyarakat "Kajian Strategis Pembangunan Kesejahteraan Sosial dan Pekerjaan Sosial. Bandung : Refika Aditama. 